\title{
Review of distributed energy storage aggregation technology under multi-energy interconnection
}

\author{
Peng Ye ${ }^{1, *}$, Shiyuan Wang ${ }^{1}$, Feng Sun ${ }^{2}$, Mingli Zhang ${ }^{3}$ and Na Zhang ${ }^{3}$ \\ ${ }^{1}$ Shenyang Institute of engineering, Shenyang, 110136, China \\ ${ }^{2}$ State Grid Liaoning Electric Power Company Limited Economic Research Institute, Shenyang, 110065, China \\ ${ }^{3}$ State Grid Liaoning Electric Power Company Limited Economic Research Institute, Shenyang, 110065, China
}

\begin{abstract}
At present, with the rapid growth of intermittent renewable energy, volatile power supply is replacing controllable power supply, and the difficulty of real-time balance between supply and demand is increasing year by year. In the future, the continuous development and utilization of this new energy will make the development and innovation of distributed energy storage technology become the general trend. Firstly, this paper briefly introduces the principle of distributed energy storage and the basic principle of multi energy coordinated operation, and analyzes its advantages and disadvantages from the perspective of economic optimization and energy utilization maximization. Secondly, it analyzes the application status and shortcomings at home and abroad, and puts forward the direction and expectation of possible breakthrough. Aiming at the problem that distributed energy storage can not participate in peak load regulation, the feasibility of multi energy interconnection distributed energy storage aggregation technology is discussed.
\end{abstract}

\section{Introduction}

With the progress of energy storage technology, cost reduction and the evolution and development of demand side, the wide application of distributed energy storage in power system is an inevitable trend of future development, and also an important way to break through the traditional planning and operation mode of distribution network ${ }^{[1]}$.

Distributed energy storage technology is the key to the safe operation of smart grid. The distribution is more flexible, and compared with centralized storage, it greatly reduces the financial pressure and later maintenance costs required to build large storage power stations. However, compared with the traditional operation mode of large power grid, the current distributed storage charging and discharging has the characteristics of poor controllability. Reasonable planning of distributed energy storage in power network and its coordinated operation with distributed power sources and loads can not only improve the economy of power network operation through peak clipping and valley filling, but also compensate for the negative impact of randomness of distributed energy storage output on power network security and economic operation, which will effectively improve the safety level and operational efficiency of power network ${ }^{[2]}$.

In this context, different types of distributed energy storage methods and mechanisms at home and abroad are sorted out and discussed in this paper, and the aggregation method of large-scale distributed energy storage is discussed, so as to provide reference and reference for improving the active support capacity of distributed energy storage in the network and carrying out further research in the future.

\section{Distributed energy storage method}

\subsection{Physical class energy storage}

\subsubsection{Pumped storage}

Pumped storage can change the surplus electric energy from low load to high value electric energy in peak period of power grid. It is also suitable for frequency modulation and phase modulation to stabilize the cycle and voltage of power system. It is also suitable for emergency reserve and can improve the efficiency of thermal power station and nuclear power station in the system ${ }^{[3-4]}$.

*Corresponding author: suozhang647@suozhang.xyz 


\subsubsection{Flywheel power storage}

Flywheel energy storage is to store energy in the form of kinetic energy to complete the energy storage process of electrical energy to mechanical energy conversion; during energy release, flywheel drives motor to generate electricity, and outputs current and voltage suitable for load through motor converter to complete the energy release process of mechanical energy to electrical energy conversion ${ }^{[5]}$.

\subsubsection{Compressed air stores energy}

Compressed air storage has attracted much attention because of its large scale, low unit cost, long life, safety and environmental protection. Its advantages of energy storage are obvious, which can make up for the congenital shortage of pumped storage, and it will be an important choice to effectively solve the large-scale energy storage problem in China.

\subsection{Chemical energy storage}

\subsubsection{Battery storage}

Battery energy storage is the most mature and reliable energy storage technology at present.

Lead acid batteries are the most commonly used energy storage system because of their mature technology, high capacity storage system, low unit energy cost and system cost, good safety, reliability and reuse. Allvanadium liquid flow battery is a new, efficient and promising energy storage technology. Compared with lead acid batteries, liquid flow batteries are non-toxic, more environmentally friendly, and can discharge $80 \%$ deep without protection, increase utilization efficiency and reduce capacity allocation requirements ${ }^{[6]}$.

\subsubsection{Superconducting magnetic energy storage}

Superconducting electromagnetic storage uses superconductors to make coils to store magnetic field energy. Power transmission does not need conversion of energy forms. It has the advantages of fast response, high conversion efficiency, specific capacity and large specific capacity. It can fully meet the requirements of voltage multiplication, power compensation, frequency adjustment, improvement of power network stability and power transmission capacity.

\subsubsection{Supercapacitors store energy}

The supercapacitor is developed according to the electrochemical double layer theory. Because of the use of special materials to make electrodes and electrolytes, the storage capacity of this capacitor is 20 to 1000 times that of ordinary capacitors, and the advantages of high energy release speed of traditional capacitors are maintained.

In recent years, with the continuous expansion of the scale of renewable energy development and utilization, the research and application of energy storage technology is increasingly extensive. The following tables show the charging and discharging characteristics of different battery energy storage technologies.

Table 1. Charge discharge characteristics of physical energy storage technology

\begin{tabular}{|c|c|c|}
\hline $\begin{array}{c}\text { Energy storage } \\
\text { type }\end{array}$ & $\begin{array}{c}\text { Typical } \\
\text { power }\end{array}$ & $\begin{array}{c}\text { Charge } \\
\text { discharge } \\
\text { duration }\end{array}$ \\
\hline $\begin{array}{c}\text { Flywheel } \\
\text { Energy } \\
\text { Storage }\end{array}$ & $\begin{array}{c}5 \mathrm{~kW} \sim 1.5 \mathrm{M} \\
\mathrm{W}\end{array}$ & $15 \mathrm{~s} \sim 15 \mathrm{~min}$ \\
\hline $\begin{array}{c}\text { Pumped } \\
\text { storage }\end{array}$ & $\begin{array}{c}100 \sim 2000 \mathrm{M} \\
\mathrm{W}\end{array}$ & $4 \sim 10 \mathrm{~h}$ \\
\hline $\begin{array}{c}\text { Air } \\
\text { compression }\end{array}$ & $\begin{array}{c}100 \sim 300 \mathrm{M} \\
\mathrm{W}\end{array}$ & $6 \sim 20 \mathrm{~h}$ \\
\hline
\end{tabular}

Table 2. Charge discharge characteristics of electromagnetic energy storage technology

\begin{tabular}{|c|c|c|}
\hline $\begin{array}{c}\text { Energy } \\
\text { storage type }\end{array}$ & $\begin{array}{c}\text { Typical } \\
\text { power }\end{array}$ & $\begin{array}{c}\text { Charge } \\
\text { discharge } \\
\text { duration }\end{array}$ \\
\hline $\begin{array}{c}\text { Superconducti } \\
\text { ng energy } \\
\text { storage }\end{array}$ & $\begin{array}{c}10 \mathrm{KW} \sim 1 \mathrm{M} \\
\mathrm{W}\end{array}$ & $5 \mathrm{~s} \sim 5 \mathrm{~min}$ \\
\hline $\begin{array}{c}\text { Super } \\
\text { capacitor }\end{array}$ & $1 \sim 100 \mathrm{MW}$ & $1 \mathrm{~s} \sim 1 \mathrm{~min}$ \\
\hline
\end{tabular}

Table 3. Charge discharge characteristics of electrochemical energy storage technology

\begin{tabular}{|c|c|c|}
\hline $\begin{array}{c}\text { Energy storage } \\
\text { type }\end{array}$ & $\begin{array}{c}\text { Typical } \\
\text { power }\end{array}$ & $\begin{array}{c}\text { Charge } \\
\text { discharge } \\
\text { duration }\end{array}$ \\
\hline $\begin{array}{c}\text { Lead-acid } \\
\text { battery }\end{array}$ & $\begin{array}{c}1 \mathrm{~kW} \sim 50 \mathrm{M} \\
\mathrm{W}\end{array}$ & $1 \mathrm{~min} \sim 3 \mathrm{~h}$ \\
\hline $\begin{array}{c}\text { Sodium sulfur } \\
\text { battery }\end{array}$ & $\begin{array}{c}100 \mathrm{~kW} \sim 100 \\
\mathrm{MW}\end{array}$ & min $\sim \mathrm{h}$ level \\
\hline $\begin{array}{c}\text { Flow batteries } \\
5 \mathrm{~kW} \sim 100 \mathrm{M} \\
\mathrm{W}\end{array}$ & $1 \sim 20 \mathrm{~h}$ \\
\hline $\begin{array}{c}\text { Lithium-ion } \\
\text { battery }\end{array}$ & $\begin{array}{c}100 \mathrm{~kW} \sim 10 \\
\mathrm{MW}\end{array}$ & min $\sim \mathrm{h}$ level \\
\hline
\end{tabular}

\section{Current situation and prospect of distributed energy storage aggregation technology}

\subsection{Distributed energy storage aggregator}

Distributed energy storage as source, load characteristics, the flexibility to implement load transfer, has quick response speed, low cost and high potential many virtues, 
such as the energy storage link is a good scheduling of power auxiliary service resources However, compared with traditional power grid operation mode, distributed energy storage was conducted by a single energy storage unit to charge and discharge action, its power and capacity is limited, if adopt the way of power system control will cause unnecessary waste and loss Aiming at this situation, you can refer to demand side management model, based on the user, power market operation for the connection way, establish the distributed energy storage aggregators Through the aggregation management of various energy storage technologies and equipment, this kind of resources can show the characteristics of flexible regulation and great scheduling potential.

\subsection{Characteristics of distributed energy storage aggregation technology}

Distributed energy storage aggregation technology is the key technology for the construction of distributed cloud energy storage platform. Through the functions of information collection and cloud computing, it realizes the aggregation management of distributed resources in a certain range, realizes the energy complementarity between distributed energy storage with different parameters, and improves the stability of power system. Aggregation technology requires that a variety of different types of distributed energy storage can be aggregated. On the premise of maintaining the stability of the power system, distributed energy storage resources can be directly or indirectly deployed to participate in the operation of the power system ${ }^{[7]}$. Therefore, distributed energy storage polymerization technology must have the following characteristics:

(1) Accuracy

The aggregation technology can be used to allocate power flow according to the characteristics of different kinds of distributed energy storage technology, and fully tap the adjustable potential of distributed energy storage

(2) Economy

The proposed distributed energy storage aggregation technology is conducive to the integration of a wide range of distributed energy storage resources in the power system, fully tap its regulatory potential, so that it can better participate in grid services. In the market environment, distributed energy storage aggregation technology can integrate energy storage resources through its professional means and participate in the main energy market or auxiliary service market ${ }^{[8]}$.

\subsection{Model planning of distributed energy storage aggregation technology}

\subsubsection{Structure design of distributed energy storage polymerization technology}

For the structure design of distributed energy storage aggregation technology, we can refer to the hierarchical control method of power system and distributed generation.

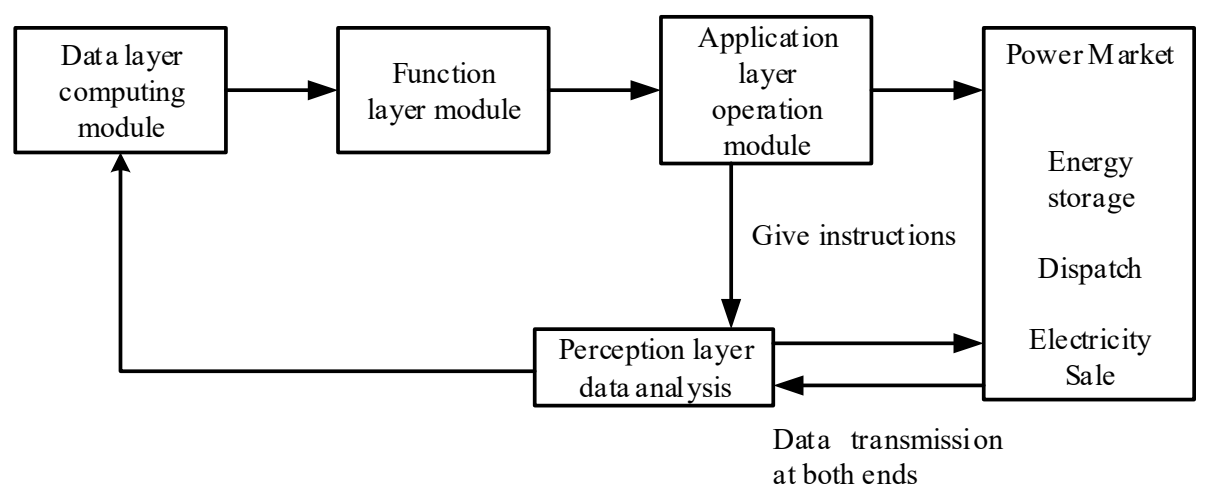

Figure 1. Structure diagram of distributed energy storage aggregation technology [9]:

The structure and function of each part are as follows

(1) The data layer contains all kinds of computer modules. The main function is to process the data collected from the power market and the data collected from the terminal energy storage device, and receive them through the perception layer.

(2) The function layer mainly includes many functional modules. Its main function is to identify the terminal energy storage parameters, group and aggregate a variety of energy storage devices, tap their regulatory potential, and formulate specific regulatory strategies based on the collected load demand, electricity price and other information of the power market.

(3) The application layer contains various operation modules. The main function is to display the collected information and perform corresponding operations, such as determining the user side power consumption and stress response in case of failure.

(4) The sensing layer includes the distributed energy storage equipment of the terminal and its supporting advanced measurement system. The main function is to sense the terminal energy storage state, and the distributed energy storage aggregation technology gives the control instructions.

(5) Electricity market refers to the external marketing, data collection and execution of specific instructions. 


\subsubsection{Distributed Energy Storage Model}

(1) Charging and discharging model of distributed energy storage

The SOC (State of Charge) increases when the storage power absorbs active power while charging, while the active power is emitted when discharging, and the SOC decreases. The formula for calculating the $\mathrm{SOC}_{t}$ value at time $t$ is

$$
\mathrm{SOC}_{1}=\left\{\begin{array}{l}
\operatorname{SOC}_{0}+\left(\frac{P_{\mathrm{ch}} \eta_{\mathrm{ch}}}{S_{\text {rate }}}-\frac{P_{\text {dis }}}{\eta_{\text {dis }} S_{\text {rate }}}\right) \Delta t, t=1 \\
\operatorname{SOC}_{t-1}+\left(\frac{P_{\text {ch }} \eta_{\text {ch }}}{S_{\text {rate }}}-\frac{P_{\text {dis }}}{\eta_{\text {dis }} S_{\text {rate }}}\right) \Delta t, t>1
\end{array}\right.
$$

In the formula: $\mathrm{SOC}_{0}$ is the $\mathrm{SOC}$ value at the initial time of energy storage; $P_{\mathrm{ch}}$ and $P_{\text {dis }}$ are the charging and discharging power from $t$ to $t-1$, respectively, with a maximum of one not zero; $\eta_{\mathrm{ch}}$ and $\eta_{\text {dis }}$ are the charging and discharging efficiencies, respectively; $\Delta t$ is a continuous period of charging and discharging; $S_{\text {rate }}$ is the rated capacity of energy storage.

(2) Restrictions on energy storage

The storage constraints include SOC constraints and charge-discharge constraints.

The constraints for SOC are

$$
\mathrm{SOC}_{\text {min }} \leqslant \mathrm{SOC}_{i} \leqslant \mathrm{SOC}_{\text {max }}
$$

In the formula, $\mathrm{SOC}_{\min }$ and $\mathrm{SOC}_{\max }$ are the minimum and maximum allowable values for energy storage SOC, respectively.

The corresponding charge and discharge constraints are

(1) Charge:

$$
\left\{\begin{array}{l}
P_{\text {ichmax }}=\min \left\{P_{\text {irate }}, \frac{\left(S O C_{\max }-S O C_{i}\right) S_{\text {rate }}}{\eta_{c h} \Delta t}\right\} \\
0<P_{\text {ich }}<P_{\text {ichmax }}
\end{array}\right.
$$

(2) Discharge:

$$
\left\{\begin{array}{l}
P_{\text {idismax }}=\min \left\{P_{\text {irate }}, \frac{\left(S O C_{i}-S O C_{\text {min }}\right) S_{\text {rate }} \eta_{\text {dis }}}{\Delta t}\right\} \\
0<P_{\text {idis }}<P_{\text {idis max }}
\end{array}\right.
$$

In the formula, $P_{\text {irate }}$ is the rated charging and discharging power of storage $i, P_{i \mathrm{ch}}$ and $P_{i \mathrm{dis}}$ are charging and discharging power of storage $i$, and $\mathrm{SOC}_{i}$ is the current SOC value of storage $i$.

\section{Summary}

Distributed energy aggregation technology is feasible. With the strong support of the policy, China's renewable energy has developed rapidly and the scale is expanding. The problems that hinder the development of distributed energy, such as grid connection and power generation technology, high cost and system limitations, will be gradually eliminated. Distributed energy refers to the energy supply system distributed on the load side. The equipment includes distributed generation equipment and distributed energy storage equipment. The energy includes both fossil fuel energy and renewable energy, such as natural gas, wind energy, solar energy, biomass energy, etc, With stable power supply, flexible dispatching, energy saving and environmental protection, small investment and other outstanding advantages, the future development prospect is broad. Distributed energy can provide power for users alone, and can also be connected with large power grid. When it supplies power for users alone, it can form micro grid with energy storage devices. In the future, distributed energy will be an important source of energy and occupy an increasingly important proportion in the energy consumption structure. The advantages of distributed energy are of great practical significance to the realization of China's energy security.

\section{Reference}

1. Zhou Huan. Study on the Key Issues of Source-Load Interaction in New Energy Power System [D]. North China Electric Power University (Beijing), 2016.

2. Li Jianlin, Huidong, Jin Wentao, etc. Large-scale energy storage technology [M]. Beijing: Machinery Industry Press, 2016:78.

3. Cheng Hua, Xu Zheng. Energy storage technology in distributed generation [J]. High voltage electrical appliances, 2003,39(3): 53-56.

4. Severe, Zhao Lifei. Application of energy storage technology in distributed generation [J]. East China Power Technology. 2006, (10): 16-19.

5. Liu Xia. Microgrid control technology with multiple distributed power sources and energy storage [D]. Zhejiang University, 2012.

6. Zhang Weiyu, Zhu Liqiu. Key technology of flywheel energy storage and its development status [J]. Journal of Electrical Technology, 2011, 26(7): 141-146

7. Yin Qukai. Modeling of large-scale distributed energy storage aggregation and its coordinated optimization control strategy [D]. North China Electric Power University, 2019.

8. Ying Wenqi. Energy Internet: Trends and Key Technologies [J]. International Finance, 2020 (02): 30-32.

9. Yuan Xiaodong, Fei Juntao, Hu Bo, Zhang Youwang, Gele. Distributed Power Supply, Storage Energy and Flexible Load Joint Dispatch Model under Resource Aggregator Mode [J]. Power System Protection and Control, 2019,47(22): 17-26. 